\title{
Suboccipital neuralgia after C1 pedicle screw insertion: do we neglect atlantooccipital joint violation? - Case report and literature review
}

\author{
Jun-Song Yang ${ }^{1 \dagger}$, Jing Li ${ }^{2 \dagger}$, Hao Chen ${ }^{1}$, Peng Liu', Chu Chen ${ }^{3}$, Tuan-Jiang Liu², Lei Chu ${ }^{4}$ and Ding-Jun Hao ${ }^{1 *}$
}

\begin{abstract}
Background: Occipital neuralgia is one of the postoperative complications of C1 lateral mass screw insertion, which was deemed to be related with the $\mathrm{C} 2$ nerve root dysfunction.

Case presentation: A 52-year-old female patient presented with gradually progressive numbness and weakness in her extremities for 6 months. X-ray and computed tomography (CT) scan revealed obvious anterior atlantoaxial dislocation (ADD), which was reducible on extensive view. Atlantoaxial pedicle screw fixation and bone graft was performed. Immediately after the operation, the neurological symptom significantly improved. The patient complained of restricted cervical rotation and suboccipital neuralgia which was exacerbated by rotation with an intensity of 7 on a visual analog scale (VAS) ranging from 0 to 10 at postoperative day 5. While a satisfactory reduction was detected in the postoperative $C$, violation of the left atlantooccipital joint was observed in the left C1 screw. Nimesulide (daily dosage of $0.2 \mathrm{~g}$ ) and bracing were recommended immediately. At the 2 month follow-up, both the neurological improvement and reduction were maintained. The VAS of suboccipital neuralgia is 3 and decreased to 1 at 6 months postoperative. Bony fusion of the left atlantooccipital joint was confirmed by $C T$ scan at 6 months postoperative. The patient complained that the suboccipital neuralgia was tolerable without the assistance of braces or medications for pain. At the 18 month follow-up, only stiffness of head flexion and rotation was observed without suboccipital neuralgia.
\end{abstract}

Conclusion: Suboccipital neuralgia after atlantooccipital joint violation of $\mathrm{C} 1$ pedicle screw placement most likely results from $\mathrm{C} 1$ nerve root irritation. As the corresponding dermatome differs from the distributing region and aggravated factor of C2 nerve root dysfunction, neuralgia due to $\mathrm{C} 1$ irritation was only localized at suboccipital region and exacerbated by rotation.

Keywords: Occipital neuralgia, Complications, Atlantoaxial instability, Atlantoaxial fixation, Atlas screw, Lateral mass, Pedicle

\section{Background}

Occipital neuralgia $(\mathrm{ON})$ is one of the postoperative complications of $\mathrm{C} 1$ lateral mass screw insertion which compromises the quality of life of patients and has been characterized by lancinating pain and dysesthesia in the occipital region. Compared to the current $\mathrm{C} 1$ lateral mass

\footnotetext{
* Correspondence: dingjun.hao@qq.com

†un-Song Yang and Jing Li contributed equally to this work.

${ }^{1}$ Department of Spine Surgery, Honghui Hospital, Xi'an Jiaotong University,

No. 76 Nanguo Road, Xi'an 710054, Shaanxi, China

Full list of author information is available at the end of the article
}

screw technique, $\mathrm{C} 1$ pedicle screw fixation which was first reported by Resnick and Benzel in 2002, is becoming the most popular technique for atlantoaxial fixation. The latter is performed with lower incidence of irritation to the C2 nerve root, a stronger pullout strength and less blood loss from the venous plexus [1-5]. In this case study, we will present a patient with severe suboccipital pain after atlantoaxial pedicle screw fixation, which was attributed to atlantooccipital joint violation of unilateral $\mathrm{C} 1$ pedicle screw insertion.

(c) The Author(s). 2019 Open Access This article is distributed under the terms of the Creative Commons Attribution 4.0 International License (http://creativecommons.org/licenses/by/4.0/), which permits unrestricted use, distribution, and reproduction in any medium, provided you give appropriate credit to the original author(s) and the source, provide a link to the Creative Commons license, and indicate if changes were made. The Creative Commons Public Domain Dedication waiver (http://creativecommons.org/publicdomain/zero/1.0/) applies to the data made available in this article, unless otherwise stated. 


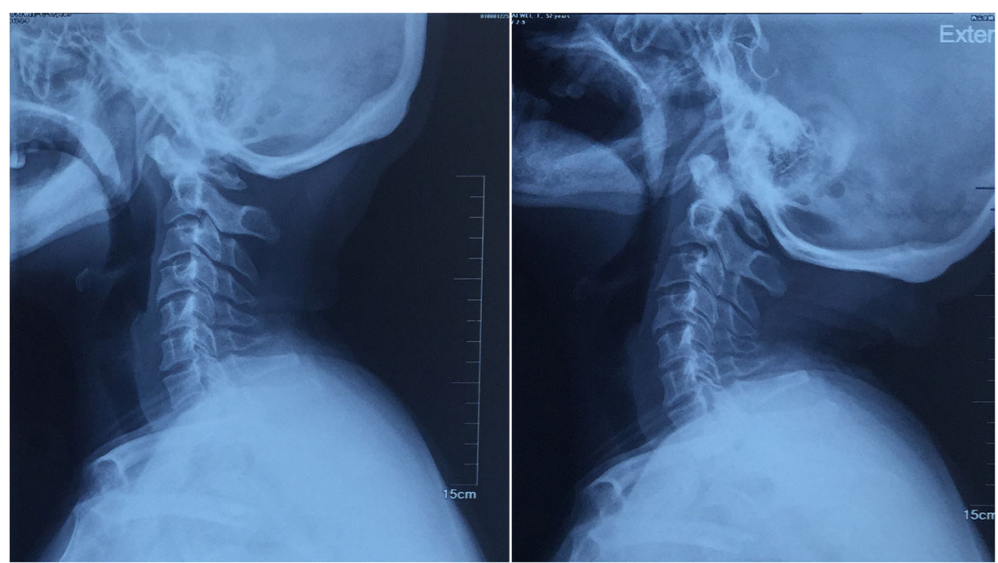

Fig. 1 X-ray revealed obvious anterior atlantoaxial dislocation (left), which was reducible on extension view (right)

\section{Case presentation}

A 52-year-old female patient presented with gradually progressive numbness and weakness in her extremities for 6 months. No obvious history of injury was reported. Physical examination evaluated the weakness of the extremities (grades 4-5 strength), especially for the bilateral handgrip muscle (grades 3-5 strength). The deep tendon reflexes in all extremities were suspected to be positive. X-ray and computed tomography $(\mathrm{CT})$ scan revealed obvious anterior atlantoaxial dislocation (ADD), which was reducible on extensive view (Figs. 1 and 2). The left side of the posterior arch was revealed as the site of defect on CT 3-dimensional imaging (Fig. 3).

During the surgery, the patient was placed in a prone position under general anesthesia, the neck was slightly extended with a Mayfield head holder. It was confirmed that the ADD was satisfactorily reduced under fluoroscopy. According to the $\mathrm{C} 1-2$ pedicle screw fixation technique reported by Resnick and Benzel [1], bilateral polyaxial screws were placed freehand into the $\mathrm{C} 1$ and
C2 pedicles and connected by 2 separated titanium rods. Decortication was accomplished by a high-speed burr into the right side of $\mathrm{C} 1$ and $\mathrm{C} 2$ lamina, and an autologous bone graft was performed.

Immediately after the operation, the neurological symptom significantly improved. The patient complained of restricted cervical rotation and suboccipital neuralgia which was exacerbated by rotation with an intensity of 7 on a visual analog scale (VAS) ranging from 0 to 10 at postoperative day 5 . While a satisfactory reduction was detected in the postoperative CT, violation of the left atlantooccipital joint was observed in the left C1 screw (Fig. 4). Nimesulide (daily dosage of $0.2 \mathrm{~g}$ ) and bracing were recommended immediately. At the 2 month follow-up, both the neurological improvement and reduction were maintained. The VAS of suboccipital neuralgia is 3 and decreased to 1 at 6 months postoperative. Bony fusion of the left atlantooccipital joint was confirmed by CT scan at 6 months postoperative (Fig. 5). The patient complained that the suboccipital neuralgia

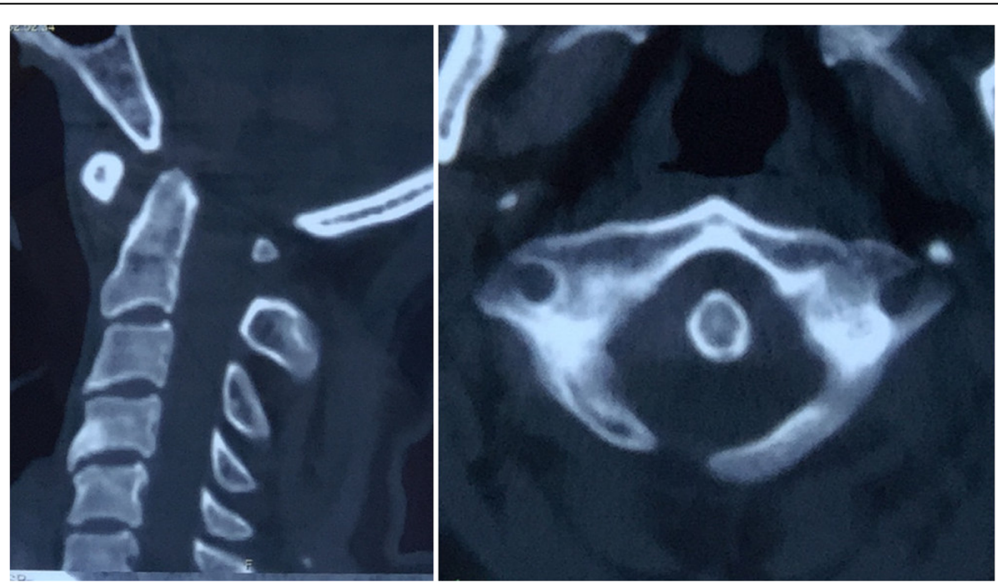

Fig. 2 Computed tomography (CT) scan revealed obvious anterior atlantoaxial dislocation 


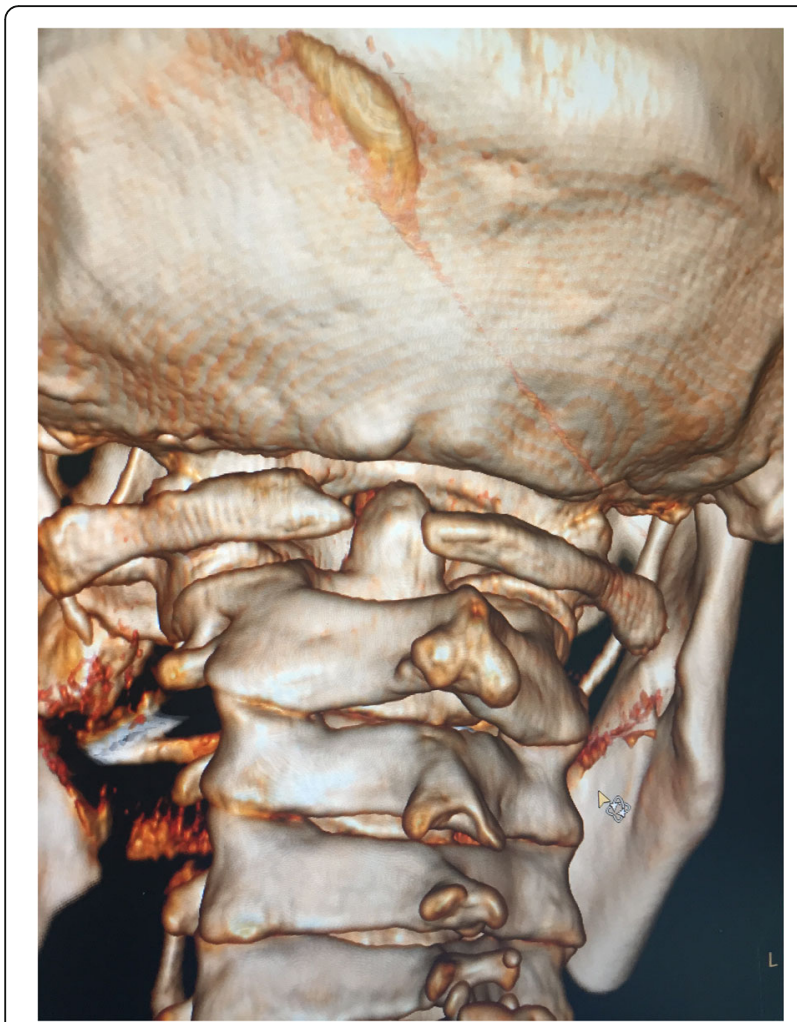

Fig. 3 The left side of the posterior arch was revealed as the site of defect on CT 3-dimensional imaging

was tolerable without the assistance of braces or medications for pain. At the 18 month follow-up, only stiffness of head flexion and rotation was observed without suboccipital neuralgia.

\section{Discussion and conclusions}

Screw violation of the facet capsule and/or the facet joint was widely explored in lumbar spine, which is believed to be associated with postoperative pain because of impingement and instability. In addition, the alterations of the normal biomechanics adjacent to the level of fixation may lead to earlier degeneration [6]. Recent studies on atlantoaxial fixation have elaborated that $\mathrm{C} 1$ lateral mass screw placement could induce $\mathrm{C} 2$ irritation which was deemed to be the determining factor in the pathogenesis of $\mathrm{ON}[2,3,5]$. Huang, et al. speculates that the difference in height between the $\mathrm{C} 2$ ganglion and its corresponding foramen could determine whether the $\mathrm{C} 2$ ganglion is impinged; when the height left for the screw in the $\mathrm{C} 1-2$ foramen was $<4 \mathrm{~mm}$, it could present a high risk of postoperative $\mathrm{C} 2$ nerve dysfunction [7]. Resnick and Benzel first reported the $\mathrm{C} 1$ pedicle screw fixation technique in 2002, which in essence inserted the $\mathrm{C} 1$ lateral mass screw via the posterior arch [1]. As the entry point was slightly lifted, compared to $\mathrm{C} 1$ lateral mass screw placement, it may provide lower incidence of $\mathrm{ON}$, resulting from irritation to the $C 2$ nerve root $[4,5]$. The bilateral $\mathrm{C} 2$ ganglion was not sacrificed during the fixation process in our case, and the irritation to $\mathrm{C} 2$ ganglion was theoretically lower as the entry point was higher. Nevertheless, it could increase the chances of the screw violating the atlantooccipital joint for some cases with small lateral mass. Due to the change in intraoperative position change and individual differences, inserting the $\mathrm{C} 1$ pedicle screw by free hand might be hard in terms of staying on the recommended direction. The osseous overlap mainly concerns the craniocervical region as it could impair the quality of intraoperative fluoroscopy. The possibility of the $\mathrm{C} 1$ pedicle screw violating the atlantooccipital joint could be reduced during the surgical procedure.

As the occipital region is the corresponding dermatome of $\mathrm{C} 1-\mathrm{C} 3, \mathrm{ON}$ is not only related with $\mathrm{C} 2$ irritation, but also with $\mathrm{C} 1$ dysfunction. As the differences in the corresponding dermatome differed from the distributing region of $\mathrm{C} 2$ nerve root dysfunction; neuralgia due to $\mathrm{C} 1$ irritation was only localized at the suboccipital
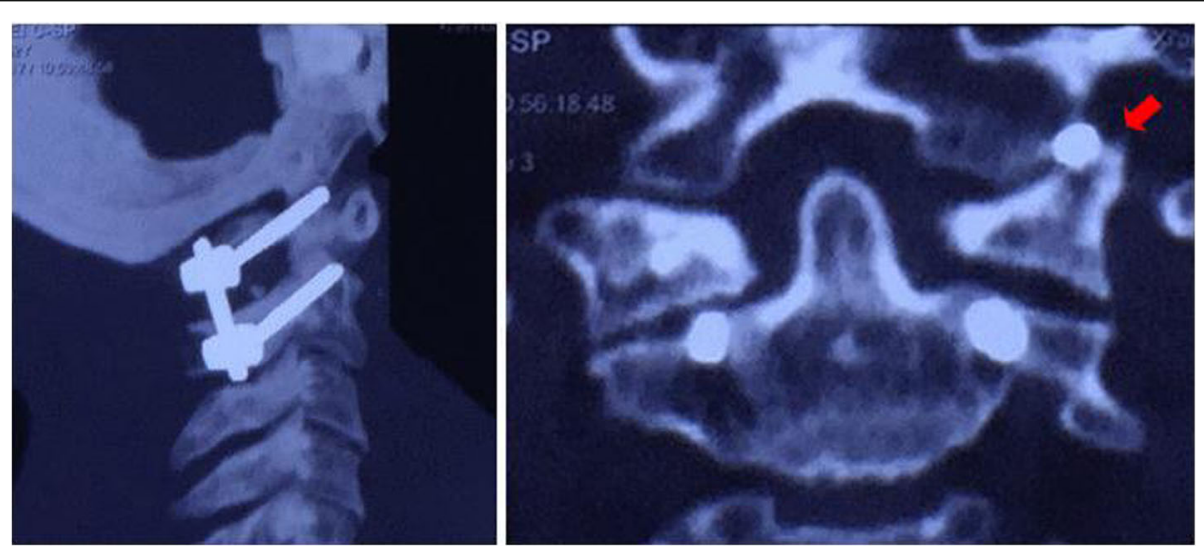

Fig. 4 While a satisfactory reduction was detected in the postoperative $C T$, violation of the left atlantooccipital joint was observed in the left C1 screw (arrow) 


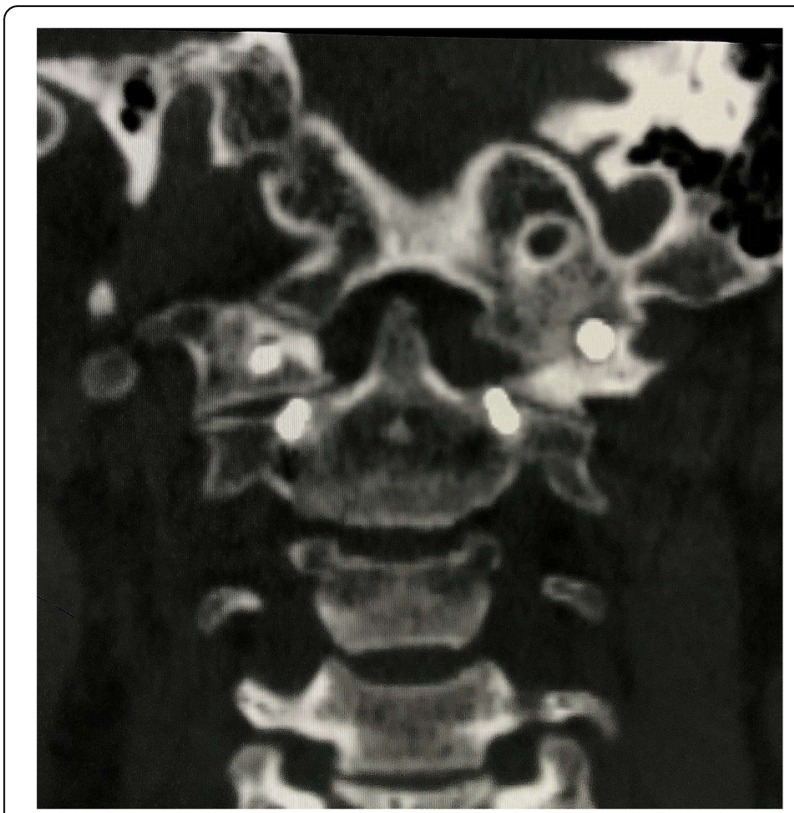

Fig. 5 Bony fusion of the left atlantooccipital joint was confirmed by CT scan at 6 months postoperativ region. Screw violation of the atlantooccipital joint could induce impingement, which explained why suboccipital pain was exacerbated by rotation.

Additionally, ON, as a symptom, was not only reported in cases after atlantoaxial fixation, but also observed in certain cases of atlantoaxial osteoarthritis (AAOA) [8]. The pathogenesis of pain in $\mathrm{ON}$ has been postulated to include direct compression of the occipital nerves, as well as micromotion of the degenerated atlantoaxial facet joint itself, with pain transmission via the anterior ramus of the $\mathrm{C} 2[8,9]$. Atlantoaxial fusion could eliminate facet micromotion; thus expecting to remove one of the primary pain generators to some degree [10]. The suboccipital nerve is the dorsal primary ramus of the first cervical nerve (Fig. 6). The atlantooccipital joint has a large range of rotation in the cervical spine secondary to the atlantoaxial joint. Similar with facet violation in the lumbar spine, screw violation of the atlantooccipital joint could induce impingement and impair the joint surface, thus leading to traumatic arthritis. Additionally, atlantooccipital joint degeneration could also generate micromotion. Any inflammatory irritation or mechanical instability could generate neuralgia which could affect the surrounding neural structure - the posterior ramus of $\mathrm{C} 1$, the so called suboccipital nerve. The

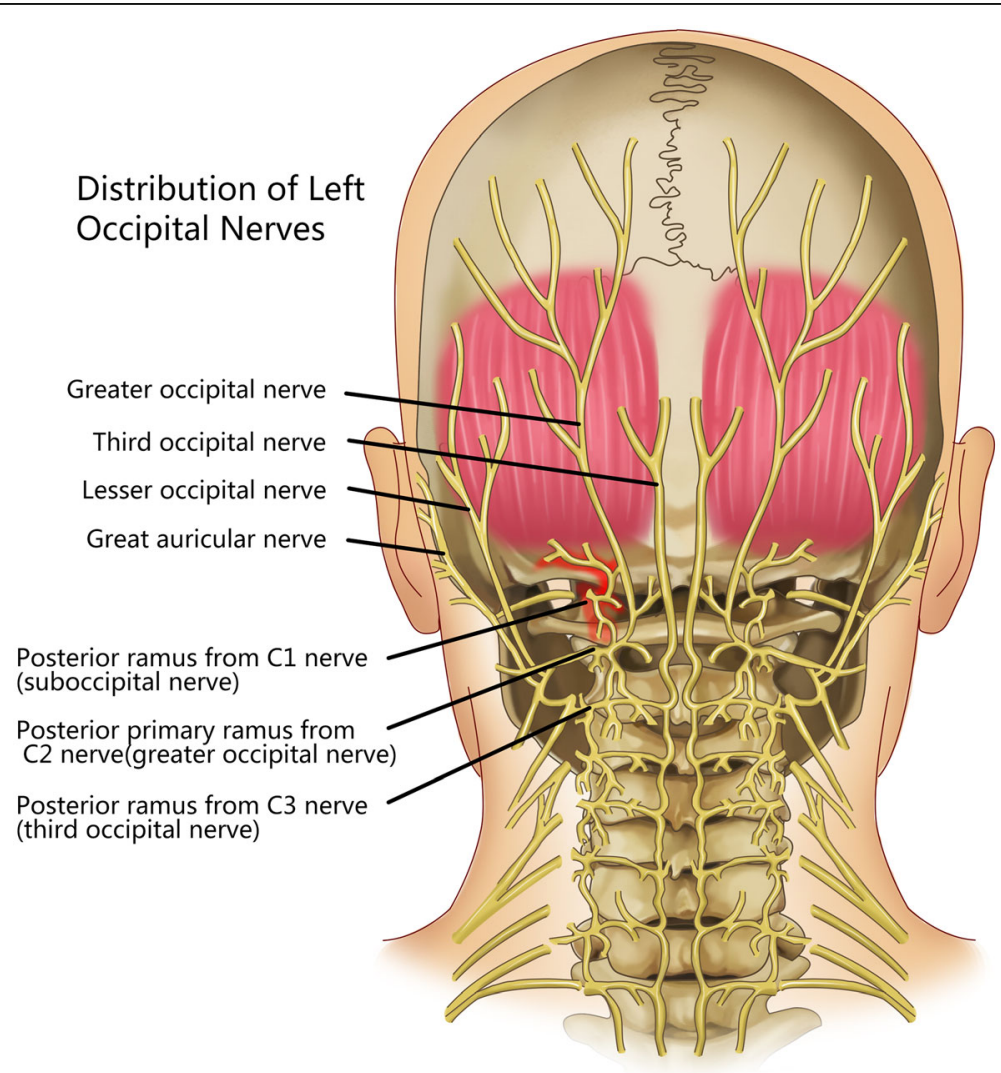

Fig. 6 The suboccipital nerve is the dorsal primary ramus of the first cervical nerve, which was highlighted by red color 
progression of osteoarthritis could lead to fibrosis or bony ankylosis. Similar as to the effectiveness of $\mathrm{C} 1-2$ fusion was for patients with intractable neck pain secondary to AAOA. The suboccipital neuralgia was finally resolved when bony fusion was formed at the left atlantooccipital joint.

$\mathrm{ON}$ is commonly idiopathic but may occur when the C1-3 nerve roots are statically or dynamically compressed after occipitocervical surgery. Suboccipital neuralgia after atlantooccipital joint violation of $\mathrm{C} 1$ pedicle screw placement most likely results from $\mathrm{C} 1$ nerve root irritation. As the corresponding dermatome differs from the distributing region and aggravated factor of $\mathrm{C} 2$ nerve root dysfunction, neuralgia due to $\mathrm{C} 1$ irritation was only localized at suboccipital region and exacerbated by rotation. In such cases, screw violation into the atlantooccipital joint after atlantoaxial pedicle screw fixation could be a neglected cause of suboccipital pain.

\section{Abbreviations}

AAOA: Atlantoaxial osteoarthritis; ADD: Anterior atlantoaxial dislocation; CT: Computed tomography; ON: Occipital neuralgia; VAS: Visual analog scale

\section{Acknowledgements}

None.

\section{Authors' contributions}

HDJ and LJ conceived the study design. LP, LTJ and CC supervised the data collection. YJS drafted the manuscript. $\mathrm{CL}$ and $\mathrm{CH}$ contributed to the revision. HDJ is responsible for this article. All authors have read and approved the manuscript.

\section{Funding}

We acknowledge the financial support received from the National Natural Science Foundation of China (81830077) in the language polishing of manuscripts.

\section{Availability of data and materials}

All data are included in the section of Case Presentation and are available from the corresponding author on reasonable request.

\section{Ethics approval and consent to participate}

The study was approved by the ethical committee of Honghui Hospital, Xi'an Jiaotong University. The patient gave written consent to for research applications of their clinical data.

\section{Consent for publication}

Written informed consent was obtained from the patient for publication of this article and any accompanying images. A copy of the written consent is available for review by the Editor of this journal.

\section{Competing interests}

The authors declare that they have no competing interests.

\section{Author details}

'Department of Spine Surgery, Honghui Hospital, Xi'an Jiaotong University, No. 76 Nanguo Road, Xi'an 710054, Shaanxi, China. ${ }^{2}$ Department of Anesthesiology, Honghui Hospital, Xi'an Jiaotong University, No. 76 Nanguo Road, Xi'an 710054, Shaanxi, China. ${ }^{3}$ Department of Clinical Laboratory, Honghui Hospital, Xi'an Jiaotong University, No. 76 Nanguo Road, Xi'an 710054, Shaanxi, China. ${ }^{4}$ Department of orthopaedics, the second affiliated Hospital of Chongqing Medical University, No. 76 Linjiang Road, Chongqing 400010, China.
Received: 21 January 2019 Accepted: 30 June 2019

Published online: 23 July 2019

\section{References}

1. Resnick DK, Benzel EC. C1-C2 pedicle screw fixation with rigid cantilever beam construct: case report and technical note. Neurosurgery. 2002;50:426-8.

2. Pan J, Li L, Qian L, et al. C1 lateral mass screw insertion with protection of C1-C2 venous sinus: technical note and review of the literature. Spine (Phila Pa 1976). 2010:35:E1133-6.

3. Conroy E, Laing A, Kenneally $R$, et al. C1 lateral mass screw-induced occipital neuralgia: a report of two cases. Eur Spine J. 2010;19:474-6.

4. Lee SH, Kim ES, Eoh W. Modified C1 lateral mass screw insertion using a high entry point to avoid postoperative occipital neuralgia. J Clin Neurosci. 2013;20:162-7.

5. Zheng Y, Hao D, Wang B, et al. Clinical outcome of posterior C1-C2 pedicle screw fixation and fusion for atlantoaxial instability: a retrospective study of 86 patients. J Clin Neurosci. 2016:32:47-50.

6. Patel RD, Graziano GP, Vanderhave KL, et al. Facet Violation with the Placement of Percutaneous Pedicle Screws. Spine (Phila Pa 1976). 2011;36: E1749-52.

7. Huang DG, Hao DJ, Jiang YH, Cheng Y, Pan JW, Qiang YQ, He BR, Qian LX The height for screw index (HSI) predicts the development of $\mathrm{C} 2$ nerve dysfunction associated with C1 lateral mass screw fixation for atlantoaxial instability. Eur Spine J. 2014;23(5):1092-8.

8. Guha D, Mohanty C, Charles H, et al. Occipital neuralgia secondary to unilateral atlantoaxial osteoarthritis: case report and review of the literature. Surg Neurol Int. 2015;6:186

9. Dreyfuss P, Michaelsen M, Fletcher D. Atlanto-occipital and lateral atlantoaxial joint pain patterns. Spine (Phila Pa1976). 1994;19:1125-31.

10. Elliott RE, Tanweer O, Smith ML, et al. Outcomes of fusion for lateral atlantoaxial osteoarthritis: meta-analysis and review of literature. World Neurosurg. 2013;80:e337-46.

\section{Publisher's Note}

Springer Nature remains neutral with regard to jurisdictional claims in published maps and institutional affiliations.

Ready to submit your research? Choose BMC and benefit from:
- fast, convenient online submission
- thorough peer review by experienced researchers in your field
- rapid publication on acceptance
- support for research data, including large and complex data types
- gold Open Access which fosters wider collaboration and increased citations
- maximum visibility for your research: over 100M website views per year
At BMC, research is always in progress.
Learn more biomedcentral.com/submissions

